NBER WORKING PAPER SERIES

\title{
INNOVATING STANDARDS THROUGH INFORMAL CONSORTIA: THE CASE OF WIRELESS TELECOMMUNICATIONS
}

\author{
Henry R. Delcamp \\ Aija Leiponen \\ Working Paper 18179 \\ http://www.nber.org/papers/w18179
NATIONAL BUREAU OF ECONOMIC RESEARCH
1050 Massachusetts Avenue
Cambridge, MA 02138
June 2012

This paper has benefitted from comments by the participants and organizers of the NBER conferencelon Standards, Patents, and Innovation (2012), particularly by Tim Simcoe, Ajay Agrawal, Shane Greenstein, and Neil Gandal, and from seminar participants at Cornell University and Stanford University. The views expressed herein are those of the authors and do not necessarily reflect the views of the National Bureau of Economic Research.

NBER working papers are circulated for discussion and comment purposes. They have not been peerreviewed or been subject to the review by the NBER Board of Directors that accompanies official NBER publications.

(C) 2012 by Henry R. Delcamp and Aija Leiponen. All rights reserved. Short sections of text, not to exceed two paragraphs, may be quoted without explicit permission provided that full credit, including (C) notice, is given to the source. 
Innovating Standards Through Informal Consortia: The Case of Wireless Telecommunications Henry R. Delcamp and Aija Leiponen

NBER Working Paper No. 18179

June 2012

JEL No. D23,L15,L23,L24

\begin{abstract}
$\underline{\text { ABSTRACT }}$
We empirically examine the effects of industry consortia on the coordination of innovation strategies of the members. Our analyses utilize membership data from 32 consortia in wireless telecommunication technology subfields from 2000 to 2005 and prior art citations in standards-essential patents. We find that connections among firms in informal technically-oriented consortia significantly increase the likelihood that firms cite each other's patents in subsequent patents essential for the UMTS wireless telecommunication standard. Inventions that are likely to become part of the UMTS telecommunication system tend to build on inventions by firm peers who were members in the same consortia, controlling for patent or firm fixed effects, technology class, and other characteristics. Consortia may enhance productivity of invention and increase the incentives to invest in R\&D by internalizing potential externalities. They may also enhance efficiency of standardization by facilitating the interaction of committee and market processes. Consortia thus structure and constrain the process of innovating standardized technologies. This is problematic if consortia are not truly accessible for all the relevant parties. Policymakers thus need to balance these effects. For managers, the results show that participation in a variety of technical consortia enables influencing peers' innovation strategies related to compatibility standards.
\end{abstract}

\title{
Henry R. Delcamp
}

CERNA

Ecole des Mines ParisTech

60 Boulevard Saint Michel

75006 Paris

France

henry.delcamp@ensmp.fr

Aija Leiponen

Cornell University

Dyson School of Applied Economics and Management

and Imperial College London Business School

Warren Hall

Ithaca NY 14853-7801

USA

aija.leiponen@cornell.edu 


\section{Introduction}

This paper examines the effects of firms' participation in wireless telecommunications industry consortia on their subsequent innovations that become declared essential patents in the global UMTS standard for mobile communication. We highlight the increasingly central role that these types of technical consortia play in coordinating technology development in many different technology fields and industries. Consortia are particularly prevalent in, but not limited to, Information and Communication Technology (ICT) industries where individual products may be associated with thousands of patents and hundreds of compatibility standards (WSJ, 2011; Biddle, 2012).

Compatibility standards are common technology norms that ensure interoperability between communication products and services ${ }^{3}$. Information and Communication Technology (ICT) standards, in particular, embody an increasing number of patented elements. In many ICT fields, particularly in telecommunications, standards have traditionally been defined cooperatively by governments or industry actors within formal Standard Setting Organizations $^{4}$ (SSOs). However, these formal SSOs are often perceived to be slow and bureaucratic, particularly when intellectual property rights have become part of the negotiation (Simcoe, 2012; Bekkers et al. 2002). For instance, the $3 \mathrm{G}$ wireless telecom standard studied here is associated with around 16000 essential patent disclosures, and its development took most of a decade.

To accelerate the process, sub-groups of firms may create less formal upstream alliances or consortia. These types of collaborative organizations offer opportunities to discuss, test, or promote certain technologies, or they can be used to actually develop new technical specifications that will subsequently be submitted to formal SSOs for official approval. The effects of these consortia have been debated in policy circles (e.g., Cargill, 2001) but there is little quantitative empirical research evidence. DeLacey et al. (2006) discuss the division of labor between formal standardization and informal consortia in the development of WiFi and DSL standards, noting that firms may use consortia to influence and accelerate formal standardization. Leiponen (2008) suggests that ICT firms' participation in such consortia enhances their ability to influence formal standard-setting outcomes. However, there is no

\footnotetext{
${ }^{3}$ E.g., mobile phones, DVD content and players, and internet protocols.

${ }^{4}$ E.g., International Standard Organization, International Telecommunication Union
} 
evidence to date about the broader implications of informal consortia for coordination of innovation in network-technological industries. The purpose of this paper is to address this research gap and conduct an empirical analysis of the effects of ICT consortia on the coordination of R\&D strategies of the participants.

Whether consortia facilitate coordination of innovation related to communication standards is interesting from both policy and managerial perspectives. From a policy standpoint, our results may inform competition policy. The economic literature (Katz and Ordover, 1990; Jorde and Teece, 1990; Choi, 1993) often considers collaborative industry organizations as a potential threat to competition because of excessive market coordination. However, consortia can be socially desirable if they reduce coordination problems around innovation. In this case, consortia might mitigate wasteful duplication of effort and increase incentives to invest in R\&D by internalizing potential externalities (d'Aspremont and Jacquemin, 1988). These arguments could lead competition authorities to adopt a lenient policy with respect to standardization consortia, because they might, overall, increase R\&D efforts and productivity.

Our analyses of industry consortia in wireless telecommunications shed new light on the process through which communication standards are being created. Development of "open standards" through a process that is not truly accessible for all the interested parties may be viewed as problematic. To the degree that essential inventions that become incorporated in the formal standard are coordinated and agreed in informal and semi-private consortia, policymakers may find it worthwhile to better understand and provide rules of the game regarding meeting procedures, membership fees particularly for small firms, terms of access, and public release of relevant information. Indeed, if consortia are used to coordinate innovation in advance of formal standard setting, there is a trade-off between the speed of development and representation of the different stakeholders. Monopolization of key technologies underpinning a widely used standard is likely to lead to excessive royalties and potential holdup that can slow down technology adoption and reduce social welfare. This would be equivalent to monopolization of an upstream market in a long and complex value chain.

From a strategic viewpoint, participation in standardization consortia may offer a venue for firms to promote their technologies and become central and powerful players in an innovation network (Ballester et al. 2006; Fershtman and Gandal, 2011). For instance, from a 
sociological perspective, Pfeffer (1981) suggests that consortium participation helps firms to access and control strategic knowledge. Nevertheless, there is little empirical evidence for this assertion. Our research aims to highlight strategies that firms may deploy to influence innovation by others - particularly innovation related to compatibility standards.

This paper utilizes a network-analytical approach that examines the effects of one-mode and two-mode network connections on subsequent patent citations. A study of two-mode networks in open-source software development by Fershtman and Gandal (2011) is closely related to ours. We combine membership data from 32 ICT consortia to identify consortium network ties between firms involved in formal standardization of wireless telecommunication technologies through Third Generation Partnership Project, or 3GPP. 3GPP is the international standard-setting organization driving the specification development for the Universal Mobile Telecommunication System, UMTS, which is one of the third-generation mobile communication systems. Additionally, we compile and analyze citations of 16000 essential patents filed by member firms in the 3GPP standardization process for UMTS. These data will be used to econometrically assess the effects of firms' participation in consortia on cross-citations of subsequent inventions. To empirically identify the causal relationship, we use a merger in the network of consortia as an exogenous event that changed the consortium connections of dozens of member firms.

According to our empirical analysis, patent holders' involvement in consortia increases the likelihood that their patents are cited by other consortium members in subsequent patents that are declared essential for the UMTS standard. This result is particularly strong for consortia that are technically oriented (as opposed to marketing oriented) or formally allied with and thus directly related to 3GPP. The result is significant only for informal consortia and does not hold for more formal organizations such as other formal standard-setting organizations (e.g., regional SSOs). It also does not hold for other patents than those subsequently declared essential for the UMTS standard. The significant relationship we find thus appears to involve informal technical consortia and patents closely related to a standard. Finally, a change in the network caused by a merger of several consortia had a significant impact on the strength of this coordination effect. Our main results are supported by a difference-in-differences analysis utilizing this source of exogenous variation. 
Our results highlight informal technical consortia as an organization form that enables sharing of knowledge and coordination of R\&D efforts related to compatibility standards in network industries. The remainder of this paper is organized as follows. Section 2 reviews the literature on consortia and discusses the conceptual foundations of our research. Section 3 explains the data collection process and the empirical methodology. Section 4 presents our empirical results and section 5 concludes.

\section{Earlier literature on technical consortia and the intended empirical contribution}

Research and development consortia have been studied extensively in various strands of literature. The advantages and drawbacks of these organizations as well as their formation process and possible impact on future alliances are now relatively well understood. Here, we will review the benefits and costs of participation as discussed in earlier studies, and finish by discussing the distinct features and implications of consortia focused on standardization rather than just R\&D.

Scholars have found substantial positive effects of consortium participation on innovation by firms. For instance, an early stream of research analyzes R\&D consortia from a theoretical standpoint and underlines financial incentives to participate therein. Katz (1986), Katz and Ordover (1990), and d'Aspremont and Jacquemin (1988) view consortia primarily as a means to share and reduce $R \& D$ expenses. Consortia may enable scale economies and reduce effort duplication among participants. Subsequent studies examine the incentives to participate when firms have asymmetric contributions (e.g., Kamien, Muller and Zang, 1992). Here, R\&D investments create knowledge spillovers. Spillovers are positive externalities that enhance the social benefits of $R \& D$ investments, but they lead to socially suboptimal investments because private incentives do not take spillovers into account. Consortia may enable the internalization of these spillovers. This positive effect has led some scholars to propose public funding of R\&D consortia (Romer and Griliches, 1993).

Two empirical papers confirm that $R \& D$ consortia lead to increased $R \& D$ investments and productivity. First, Branstetter and Sakakibara (1998) analyze a sample of Japanese consortia and find that the marginal effect of consortium participation is about two percent increase in total R\&D spending and between four and eight percent increase in patenting per R\&D dollar 
(research productivity). In a subsequent paper, Sakakibara (2001) finds an even more substantial effect of consortium participation on R\&D expenses (around 9\%) and also finds support for the hypothesis that diverse competencies of members enhance the efficiency of the consortium, thus leading to greater R\&D expenditures by participants (see also Chung, Singh and Lee, 1999).

An organization-theoretic literature suggests that participation in $R \& D$ consortia facilitates obtaining a strategic advantage over competitors. Pfeffer (1981) proposes that consortium participation helps firms to access and control strategic knowledge. Aldrich et al. (1998) also argue that $\mathrm{R} \& \mathrm{D}$ consortia could help to orient research in the industry in a way that supports the firm's strategy. This hypothesis is supported empirically by Leiponen (2008) who examines consortia around the Third Generation Partnership Project (3GPP), a formal standards-development organization. That study finds that participation in technical consortia significantly enhances firms' contributions to new standard specifications in 3GPP committees. Firms that are central in the consortium network are ultimately better able to influence the standard-setting outcome. From a societal point of view, industry consortia may also have adverse effects and are potentially a way to foreclose competition. This potential negative effect of consortia on competition has also been discussed in a series of earlier papers (e.g. Brodley (1990), Katz and Ordover (1990), Jorde and Teece (1990) and Choi (1993).

Finally, a set of studies identifies consortia as a channel for signaling strategies within the industry. In a longitudinal study of 87 cellular service providers and equipment manufacturers, Rosenkopf, Metiu and Georges (2001) show that participation in technical committees helps to identify potential alliance partners and opportunities for collaboration. These authors also find that the marginal effect of consortium participation on alliance formation is decreasing with the number of alliances already formed and varies according to interpersonal connections. This importance of interpersonal bonds is also underlined by Dokko and Rosenkopf (2010), who examine how job mobility of individuals affects firms' abilities to influence others in a technical standard-setting committee for U.S. wireless telecommunications. The authors suggest that recruitment of employees with abundant social capital in consortium committees increases a firm's power to influence standard setting through such committees. 
As described above, cooperative research arrangements can be very beneficial, but consortium participation may also be associated with risks and costs. First, firms have to support expenses such as membership fees, and travel, meeting, and human resource costs. Sakakibara's (2001) analysis of Japanese consortia and Hawkins' study of ICT consortia (1999) present evidence that consortium participation engenders substantial costs. Hawkins' estimate of membership fees for a typical technology firm in the mid-1990s was in the order of 1.5 million US dollars. This number does not include the travel and human resource costs of participation. Moreover, in the years since this study, membership fees and the number of consortia have considerably increased. According to the data cited in DeLacey et al. (2006: 2), it was estimated in 2005 that IBM's total standard-setting investments amounted to half a billion US dollars. ${ }^{5}$

Consortia can also present risks of technology leakage. Sharing R\&D knowledge in technical meetings with other participants that have sufficient skills to understand and absorb these competencies strongly increases the risks of imitation. Kodama (1986) suggests that firms participating in consortia may create internal research groups just to absorb knowledge from consortium work. For consortium members, secrecy is thus no longer an effective protection method and member firms may need to follow alternative appropriation strategies (e.g., Leiponen and Byma (2009).

To summarize, extant literature on $R \& D$ consortia has identified many potential strategic benefits and drawbacks of participation and discussed implications for competition policies. However, most of the work on consortia has examined R\&D consortia, whereas here the focus is on standardization-related consortia. These types of collaborative structures are increasingly common. We found dozens within wireless communications alone; computing is another field where pre-standardization is often organized through informal consortia. The well-known battle for dominance in high-definition DVD formats also featured competing consortia. The European Committee for Standardization (CEN) maintains a list of over 200 important international multi-vendor ICT consortia and admits that "Much of the key standardization activity in ICT is carried out by industry consortia rather than in formal standards organizations such as CEN and ISO.” (CEN, 2012).

As discussed by Farrell and Saloner (1988: 237), formal standardization committees do many things. They share information, design product features, negotiate technical solutions, and

${ }^{5}$ http://www.forbes.com/2005/09/26/ibm-software-investments-cz_qh_0926ibm.html, retrieved on 4/6/2012. 
carry out performance and compliance tests of the proposed standards and associated products. Informal consortia do many of the same things, to varying degrees. Some consortia only share information and promote a specific set of technologies, whereas others may additionally be actively engaged in joint $R \& D$ - designing features and technical specifications - the results of which may subsequently be submitted for approval in formal standardization organizations such as $3 \mathrm{GPP}$.

Rules, decision-making processes and antitrust implications of (more) formal standard-setting organizations have been discussed in academic literature (e.g., Lemley, 2002; Anton and Yao, 1995; Chiao, Lerner, and Tirole, 2007) and also scrutinized in antitrust enforcement (e.g., see legal references in Lemley, 2002). In contrast, informal industry consortia have rarely been examined in detail either by academics or policymakers (but note Cargill's testimony in United States Congress, 2001). In fact, it is often difficult to get information about their inner functioning. Because informal consortia are private organizations, little is known about the nature and topics of discussion, decision-making procedures, or forms of information exchange.

Strategic knowledge sharing, co-development, and alignment may have long-term implications for an industry. In contrast to R\&D consortia that also develop technologies for the participant firms to offer in their new products or processes, pre-standardization consortia may develop technologies and make decisions that not only the participants but also the rest of the industry will have to abide by if they build products for the same compatibility standard. Early-stage standardization consortia may thus provide a somewhat opaque route to domination of a standard for a small subset of firms in the industry.

Indeed, informal consortia may be aware of the potential competitive implications of their activities. The Antitrust Guidelines of one such consortium in our dataset state: "The Forum is not a standard-setting organization and neither it nor any committee or member thereof shall make any effort to bring about the standardization of any product or service for the purpose or with the effect of preventing the manufacture, sale or supply of any product or services not conforming to a specified standard(...)" and "To the extent that The Forum through its committees and membership, develops or approves specifications which, if followed, will permit specific equipment and service to interoperate with any other equipment, service or network, adherence to such specifications shall be voluntary on the part of the members of 
The Forum(...)" (MWIF, 2000). This forum thus explicitly acknowledges that the development of formal standards through informal consortia might be detrimental to competition. Nevertheless, such voluntarily adopted consortium specifications may be successfully fast-tracked in a formal standardization body such as 3GPP, with the described effect of foreclosing competition.

The focus of our empirical work is on the hypothesis that pre-standardization consortia facilitate coordination of $\mathrm{R} \& \mathrm{D}$ that results in essential inventions related to a compatibility standard. If this is true, then these types of consortia may support and structure the identification of early-stage investments that enable controlling the standard later on. In the language of Farrell and Saloner (1988), consortia may be viewed as a "hybrid" coordination structure that combines market-based and committee-based processes of standardization. Consortia facilitate firms' attempts to both mobilize a market bandwagon and to negotiate and coordinate technical features with rivals. Technical meeting discussions in consortia enable negotiation and coordination, whereas competition among consortia and broader adoption of their proposals may help set off a bandwagon effect. Farrell and Saloner's theoretical work suggests that consortia can be welfare improving because they are likely to speed up coordination. However, their analysis does not examine the implications of restricted access to the early-stage processes or monopolization of the IP market (but see Simcoe and Farrell, 2011).

Policy makers such as those in the European Commission have expressed concerns that private consortia tend to be closed and undemocratic (Egyedi, 2001). Industry practitioners have also suggested that informal consortia tend to be founded by a core group of members who fix the agenda and the bylaws before others are allowed to join, often preserving membership tiers that separate founders from general members. Many consortia such as the Open Mobile Alliance included in the sample here also have multiple levels of membership differentiated by a steep fee structure, whereby it can be prohibitively expensive for smaller firms to participate in the "sponsor" levels, whereas members on lower levels are likely to be excluded from committee chairpersonships, formal votes, or rights to submit technical appeals.

As discussed by Anton and Yao (1995), agenda control alone can be a significant source of power. Moreover, dispute resolution mechanisms analyzed by Chiao, Lerner and Tirole 
(2006) are usually missing from informal consortia (such as WAP Forum that is included in their analyses and in the sample here). Then, if the basic technological approaches have already been selected at founding to support the competitive advantages of the founders, it can be difficult for newcomers to change the technical specifications already under way.

Echoing the statement by CEN cited earlier, Hawkins (1999) notes that, in telecommunications, "an international system has evolved in which communication and coordination is achieved primarily through inter-organisational alliances[...]" (also see Aldrich et al., 1998). However, systematic empirical evidence regarding firms' innovation and standardization strategies therein and their economic implications remains scarce. Our paper targets this research gap by examining the role played by consortia as vehicles for coordination of innovation in the context of ICT standardization. Specifically, we are interested in the degree to which communication in early-stage technical consortia drives innovation that becomes incorporated in formal standard specifications in a later stage.

\section{Data and Methods}

Our main empirical model tests whether consortium participation by a firm increases the likelihood that its patent is cited by other members of the same consortia in their patents that are declared as essential for the wireless telecommunication system UMTS. We thus analyze whether the likelihood that a patent is cited depends on the position and centrality of the patent holder in the network of consortia in the year in which the citing patent was applied. We test for the effect of consortium connections on the likelihood of citation at the level of cited patents and at the level of firm pairs.

We assume that patent citations primarily represent spillovers of technical knowledge, but we also consider the possibility that citations may be strategic and reflect strategic alignment among firms. According to Hall, Jaffe and Trajtenberg (2001:15), a prior art citation is essentially an acknowledgement that the invention builds on an aspect of a prior invention over which the new invention cannot have a claim. A prior art citation thus delimits and defines the breadth of an invention. At the same time, a citation also increases the probability that a patent is found to be valid (Allison and Lemley, 1998). Lampe (2012) suggests that strategic citation is widespread; ICT firms strategically leave out up to $41 \%$ of relevant and known citations to patents that they decide to ignore in an attempt to maximize the returns on 
their own R\&D investments. For the purposes of our study, we assume that the reason why co-memberships in consortia may induce cross-citations of patents is that firms learn technical information from each other in the consortium working groups and become more likely to build on each other's inventions. However, by comparing different types of consortia (technically vs. marketing oriented) and different types of firms (operating companies and non-practicing entities) we also assess the possibility that citations are primarily strategic.

We focus on citations by patents that subsequently become declared as essential for the UMTS standard, because we are interested in the ability of consortium activities to influence the set of technologies that become incorporated in the standard, but we also test the effects on citations from a broader set of patents by the same firms, and on total numbers of essential patents.

This paper relies on a combination of data on consortium co-membership links between firms involved in the third-generation mobile standards and cross-citations of patents filed by these participants. First of all, we gathered data on 16000 patents declared essential for the UMTS standard $^{6}$. We retrieved these data in October 2010 using the ETSI online patent database ${ }^{7}$. We then merged these data with information on citations using the 1976/2006 National Bureau of Economic Research database ${ }^{8}$ and used the EPIP database to identify the patent holders of the cited patents ${ }^{9}$. Appendices 1 and 2 present some information about the timing of application and technological class of patents in our sample. The citing patents are very concentrated in terms of technological class, whereas the cited patents are quite diverse. The cited patents were granted between 1976 and 2004 but the majority of them were granted in the late 1990 s or early 2000 s.

Next, we created a database on consortium membership links between firms involved in thirdgeneration mobile standards. This database is partly based on Leiponen (2008). Consortia were initially identified from press releases by wireless technology companies and from existing consortium lists compiled by Updegrove (2010), Chiao et al. (2007) and CEN (2012), and by examining whether the technology is relevant for wireless communications and whether some members of $3 \mathrm{GPP}$ were also members of the consortia. Using the Internet

\footnotetext{
${ }^{6}$ The projects included are : 3GPP, 3GPP release 7, 3GPP/AMR-WB+, UMTS, UMTS Release 5, UMTS Release 6, UMTS Release 7, UMTS Release 8, UMTS/CDMA

${ }^{7}$ Available at: http://ipr.etsi.org/

${ }^{8}$ Available at: http://www.nber.org/patents/

${ }^{9}$ Available at: http://www.epip.eu/datacentre.php
} 
Archive, we obtained data on the memberships of the patent holders (owners of the citing and the cited patents) in ICT consortia from 2000 to 2005. Some of these consortia are formally allied with $3 \mathrm{GPP}$ as organizational or marketing partners, and others are unrelated or even directly competing with 3GPP. A list of these consortia is presented in Appendix 3. A handful of relevant consortia had blocked their historical websites from the Archive and we were unable to retrieve their membership rosters.

As we have information on participation in consortia from 2000 to 2005, we will restrict our analysis of citing patents applied in this period. We organize our database around the cited patents over six years. This database consists of 1046 patents that were cited at least once by a UMTS essential patent between 1998 and 2005. These patents were held by 43 different firms ${ }^{10}$. The database connects the cited patents with 1962 citing patents, held by 17 firms.

We first examine the research question using cited patents as our unit of analysis. Our dependent variable here is a binary indicator for whether a patent was cited by a patent application that was subsequently declared as essential for the UMTS wireless telecommunication system developed in 3GPP. We use two different explanatory variables to capture firms' participation in pre-standardization consortia. These two variables measure the patent holder's general level of participation in consortia of the ICT field: the number of consortium memberships, (total memberships) and the number of unique connections to peers from consortia (consortium connections). A consortium connection is formed if two firms meet in at least one of the consortia during the year. In network-analytical terms these are two-mode and one-mode degree centrality measures, respectively (cf. Fershtman and Gandal, 2011). We include a control variable to proxy for firms' formal standardization strategies. We trace patent holders' activities in the standards-development committees of $3 \mathrm{GPP}^{11}$ and create the $3 G P P$ connections variable that equals the number of unique connections (one-mode degree centrality) to other firms through work-item committees. This variable allows us to take into account the centrality of the firm in formal standard setting and thus to distinguish the effects of informal and formal standardization strategies on cross-citations. We also include patent age dummies to control for the evolution of citation patterns over time. We estimate the following model:

\footnotetext{
${ }^{10}$ A list of the patent holders of the cited patents is presented in appendix 4.

${ }^{11}$ Using the website http://www.3gpp.org/
} 
$\operatorname{Pr}\left(\right.$ Citation $\left._{i t}\right)=\alpha_{0}+\alpha_{1}$ Consortium $_{\text {participaion }}$ pat $_{2}+\alpha_{2} 3 G P P_{-}$connectioß $_{t t}+\alpha_{3}$ Patent_age $_{p t}+\varepsilon_{p t}$ [1]

$\operatorname{Pr}\left(\right.$ Citation $\left._{\text {pit }}\right)=$ Probability of patent $p$ held by firm $i$ being cited by another 3GPP participant's patent application in year $t$

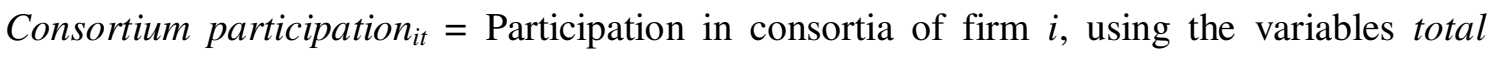
membership and consortium connections in year $t$

$3 G P P$ connections $_{i t}=$ Firm $i$ 's one-mode degree centrality in formal standardization in 3GPP committees in year $t$

Patent age $e_{p t}=$ Set of dummies for the cited patent age

$\varepsilon_{p t}=$ Error term

Table 1 describes the main estimation variables.

Table 1: Name and description of the main explanatory variables

\begin{tabular}{|l|l|c|c|c|c|}
\hline \multicolumn{1}{|c|}{ Variable } & \multicolumn{1}{|c|}{ Description } & Mean & $\begin{array}{c}\text { Std. } \\
\text { dev. }\end{array}$ & Min & Max \\
\hline Total memberships it $_{\text {t }}$ & $\begin{array}{l}\text { Number of cited firm's annual } \\
\text { memberships (two-mode network } \\
\text { degree) in consortia }\end{array}$ & 8.11 & 6.65 & 0 & 24 \\
\hline $\begin{array}{l}\text { Consortium } \\
\text { connections }_{\text {it }}\end{array}$ & $\begin{array}{l}\text { Number of cited firm's annual } \\
\text { unique connections (one-mode } \\
\text { network degree) through consortia }\end{array}$ & 124.16 & 99.23 & 0 & 280 \\
\hline 3GPP connections it $_{\text {f }}$ & $\begin{array}{l}\text { Number of unique (one-mode } \\
\text { degree) connections to other firms } \\
\text { through 3GPP work-item (formal } \\
\text { standardization) committees }\end{array}$ & 16.02 & 17.73 & 0 & 63 \\
\hline Patent applications & Number of patent applications & 651.65 & 614.91 & 0 & 5312 \\
\hline Patent age dummies & $\begin{array}{l}\text { Set of dummies for the age of the } \\
\text { cited patent }\end{array}$ & & & & \\
\hline
\end{tabular}

We thus work with a panel database of patents cited by at least one UMTS essential patent and estimate a fixed-effect conditional logit model with the likelihood to be cited at year $t$ for patent $p$ as the dependent variable. Table 2 presents the numbers of years in which the patents in our sample are cited between 1998 and 2005. The dataset contains a small number of patents that were cited every year during the period of study (2000-2005). Firms with the greatest number of patents cited in five or more years include Qualcomm (29 such patents), Motorola (16 patents), InterDigital (14), AT\&T Wireless (12) followed by NEC, Siemens, 
and Mitsubishi. Patents that are cited many times and over a long period of time are likely to represent fundamental inventions in the standardized communication system.

Table 2: Number of years the patent is cited (1998-2005)

\begin{tabular}{|c|c|}
\hline $\begin{array}{c}\text { Number of years the patent } \\
\text { is cited }\end{array}$ & Observations \\
\hline 1 & 547 \\
\hline 2 & 268 \\
\hline 3 & 86 \\
\hline 4 & 43 \\
\hline 5 & 64 \\
\hline 6 & 12 \\
\hline 7 & 23 \\
\hline 8 & 3 \\
\hline
\end{tabular}

The main empirical issue is to disentangle the effects of participation in consortia and technological strategies of firms. A patent can be highly cited because of the patent holders' participation in consortia or because the invention is technologically central in the UMTS wireless system being standardized within $3 \mathrm{GPP}$, for which reason its holder may participate in many consortia. Innovations emerging during the period of study thus might make firms more likely to both attend certain consortia and cite their central members. In order to control for these confounding factors, we deploy a number of empirical tactics: we include a control variable for firms' formal standardization strategies; we utilize standard panel-data methods (fixed effects estimation) to remove time-invariant unobserved heterogeneity; and we utilize an exogenous source of variation to reduce potential time-variant unobserved heterogeneity. However, the last approach only works for our main result regarding whether industry consortia influence subsequent standards-related innovation. For identification of the additional results on the types of consortia, we need to rely on the two former approaches.

The exogenous event we exploit for identification is a merger of seven industry consortia that shifted the consortium connections of some but not all firms in our dataset. In late 2002, seven of the consortia in our database ${ }^{12}$ merged to create the Open Mobile Alliance (OMA). OMA was formed by nearly 200 companies including mobile operators, device and network suppliers, information technology companies and content and service providers. Therefore we argue that individual firms were unlikely to have substantial influence in the merger. The

\footnotetext{
${ }^{12}$ Wap Forum, Wireless Village, SyncML Initiative, MGIF, LIF, MWIF, and UMTS Forum.
} 
stated reasons for the merger were increasing interactions and synergies between the technology fields of the seven component consortia: "The purpose of OMA is to address areas that previously fell outside the scope of any existing organizations, as well as streamline work that may have been previously duplicated by multiple organizations." 13 As a result of the merger, consortium connections of some firms increased and those of other firms decreased. We use this merger to estimate a differences-in-differences model and examine the robustness of our fixed-effects results.

\section{Estimation results}

We first run a fixed-effect model estimating the likelihood of a patent to be cited by another patent that was declared as essential for the UMTS standard, held by another consortium participant. We control for the age of the cited patent. The results of this model are presented in Table 3.

Table 3: The effect of consortium participation on the likelihood of citation

(1)

\begin{tabular}{|c|c|c|c|c|}
\hline & $\begin{array}{l}\text { Coef. } \\
\text { (SE) }\end{array}$ & $\begin{array}{l}\text { Odds ratio } \\
\text { (SE) }\end{array}$ & $\begin{array}{l}\text { Coef. } \\
\text { (SE) }\end{array}$ & $\begin{array}{l}\text { Odds ratio } \\
\text { (SE) }\end{array}$ \\
\hline Total memberships & $\begin{array}{c}0.0341 * \\
(0.019)\end{array}$ & $\begin{array}{c}1.0347^{*} \\
(0.019)\end{array}$ & & \\
\hline Consortium connections & & & $\begin{array}{c}0.0028^{* *} \\
(0.001)\end{array}$ & $\begin{array}{c}1.0028^{* *} \\
(0.001)\end{array}$ \\
\hline 3GPP connections & $\begin{array}{c}0.0128 * * * \\
(0.003)\end{array}$ & $\begin{array}{c}1.0129 * * * \\
(0.003)\end{array}$ & $\begin{array}{c}0.0168 * * * \\
(0.003)\end{array}$ & $\begin{array}{c}1.0169 * * * \\
(0.003)\end{array}$ \\
\hline Patent age dummies & \multicolumn{2}{|c|}{$\mathrm{Y}$} & \multicolumn{2}{|c|}{$\mathrm{Y}$} \\
\hline Observations & \multicolumn{2}{|c|}{6184} & \multicolumn{2}{|c|}{6184} \\
\hline Groups & \multicolumn{2}{|c|}{1043} & \multicolumn{2}{|c|}{1043} \\
\hline $\mathrm{Chi}^{2}$ & \multicolumn{2}{|c|}{685.09} & \multicolumn{2}{|c|}{689.66} \\
\hline Prob $>$ chi $^{2}$ & \multicolumn{2}{|c|}{0} & \multicolumn{2}{|c|}{0} \\
\hline Log Likelihood & \multicolumn{2}{|c|}{-1575.19} & \multicolumn{2}{|c|}{-1572.85} \\
\hline Cited firms & \multicolumn{2}{|c|}{43} & \multicolumn{2}{|c|}{43} \\
\hline
\end{tabular}

Notes: Dependent variable is an indicator for whether a patent was cited by an essential patent applied in year $\mathrm{t}$. Estimation method is conditional logit with fixed effects at the patent level. Unit of analysis is the cited patent. Standard errors, clustered on patents, in parentheses under the coefficients. ${ }^{*} \mathrm{p}<.10 ; * * \mathrm{p}<.05 ; * * * \mathrm{p}<.01$

\footnotetext{
${ }^{13}$ http://www.openmobilealliance.org/AboutOMA/FAQ.aspx, retrieved 8/2/2002.
} 
According to the basic fixed-effects results at the level of the cited patent as shown in table 3, the two main explanatory variables, the cited patent holder's total number of memberships in wireless industry consortia and their unique consortium connections to peers both have at least weakly statistically significant and positive effects on the likelihood of a patent to be cited by another consortium participant. Odds ratios suggest that one additional membership increases the odds of citation by $3.5 \%$, whereas one additional connection increases the odds of citation by $0.3 \%$. These effects are aligned in the sense that one additional membership may generate dozens of new connections. The coefficient of $3 G P P$ connections that controls for firms' connections to peers through formal standardization activities is significant and positive, suggesting that similar information is exchanged in formal standards committees (cf. Bekkers et al. 2011).

Next, we use the exogenous event, a merger of seven consortia in 2002, to examine the robustness of our main result. When Mobile Games Interoperability Forum (MGIF), UMTS Forum, WAP Forum, Wireless Village, SyncML Initiative, Location Interoperability Forum (LIF) and Mobile Wireless Internet Forum (MWIF) merged to form Open Mobile Alliance, the consortium connections of the members of the seven consortia were exogenously shifted. Firms included in the control group who were members of none of the consortia affected by the merger are listed in appendix 5. We thus dissect the participation effect found in table 3 with respect to timing and OMA vs. other consortia. The results are presented in table 4.

The OMA connections variable (number of unique connections through OMA or its constituent consortia) has a positive and statistically significant effect on citations. OMA and the component consortia were thus probably central venues for discussing ongoing innovation. In fact, the effect of connections from other consortia (other connections) is statistically insignificant here. The most relevant coefficient in table 4 is that on the variable OMA connections after that measures the additional effect of OMA-related connections after the merger. This effect is statistically borderline significant at the $5 \%$ level in the two specifications. 


\section{Table 4: Impact of the OMA merger on subsequent citations}

\begin{tabular}{|c|c|c|c|c|}
\hline & \multicolumn{2}{|c|}{ (1) } & \multicolumn{2}{|c|}{ (2) } \\
\hline & $\begin{array}{l}\text { Coef. } \\
\text { (SE) }\end{array}$ & $\begin{array}{l}\text { Odds ratio } \\
\text { (SE) }\end{array}$ & $\begin{array}{l}\text { Coef. } \\
\text { (SE) }\end{array}$ & $\begin{array}{c}\text { Odds ratio } \\
\text { (SE) }\end{array}$ \\
\hline OMA connections & $\begin{array}{c}0.0028 * * \\
(0.001)\end{array}$ & $\begin{array}{c}1.0028^{* *} \\
(0.001)\end{array}$ & $\begin{array}{c}0.0036^{* * *} \\
(0.001)\end{array}$ & $\begin{array}{c}1.0036^{* * * *} \\
(0.001)\end{array}$ \\
\hline $\begin{array}{l}\text { Other consortium } \\
\text { connections }\end{array}$ & $\begin{array}{c}0.0003 \\
(0.0003)\end{array}$ & $\begin{array}{l}1.0003 \\
(0.0003)\end{array}$ & $\begin{array}{c}0.0001 \\
(0.0003)\end{array}$ & $\begin{array}{c}1.0001 \\
(0.0003)\end{array}$ \\
\hline OMA connections after & $\begin{array}{c}0.0045^{* *} \\
(0.002)\end{array}$ & $\begin{array}{c}1.0045^{* *} \\
(0.002)\end{array}$ & $\begin{array}{c}0.0042 * \\
(0.002)\end{array}$ & $\begin{array}{l}1.0042 * \\
(0.002)\end{array}$ \\
\hline Dummy after & $\begin{array}{c}-2.0055^{* * *} \\
(0.262)\end{array}$ & $\begin{array}{c}0.1346^{* * * *} \\
(0.035)\end{array}$ & $\begin{array}{c}-2.0851^{* * *} * \\
(0.266)\end{array}$ & $\begin{array}{c}0.1243 * * * \\
(0.033)\end{array}$ \\
\hline 3GPP connections & & & $\begin{array}{c}-0.0097 * * \\
(0.004)\end{array}$ & $\begin{array}{c}0.9904 * * * \\
(0.004)\end{array}$ \\
\hline Patent age dummies & \multicolumn{2}{|c|}{$\mathrm{Y}$} & \multicolumn{2}{|c|}{$\mathrm{Y}$} \\
\hline Observations & \multicolumn{2}{|c|}{6184} & \multicolumn{2}{|c|}{6184} \\
\hline Groups & \multicolumn{2}{|c|}{1043} & \multicolumn{2}{|c|}{1043} \\
\hline Chi 2 & \multicolumn{2}{|c|}{742.75} & \multicolumn{2}{|c|}{785.07} \\
\hline Prob $>$ chi 2 & \multicolumn{2}{|c|}{0} & \multicolumn{2}{|c|}{0} \\
\hline $\begin{array}{l}\text { Log Likelihood } \\
\text { Cited firms }\end{array}$ & \multicolumn{2}{|c|}{-1500.01} & \multicolumn{2}{|c|}{-1479.32} \\
\hline
\end{tabular}

Notes: Dependent variable is an indicator for whether a patent was cited by an essential patent applied in year t. Estimation method is conditional logit with fixed effects at the patent level. Standard errors, clustered on patents, are in parentheses under the coefficients. ${ }^{*} \mathrm{p}<.10 ;{ }^{* *} \mathrm{p}<.05 ; * * * \mathrm{p}<.01$

In table 5 we return to the basic fixed-effect approach to further distinguish the effects of different types of consortia, which we cannot examine with the diff-in-diff method because OMA and its constituent consortia are all informal and technical in nature. We first distinguish between formal and informal consortia. Formal consortia are standard-setting organizations (SSOs) that draft and certify formal standards whereas informal consortia may develop, discuss, test, and promote technological alternatives, but they submit their specifications (if any) to formal SSOs for certification. We expect informal consortia to be more conducive to influencing peers, because their less formal and structured ex-ante discussions can be more easily used to promote the members' technologies that might be utilized or built on in the formal standard-setting context of $3 \mathrm{GPP}$.

Consortia can also be formally allied (related) with 3GPP or unrelated with 3GPP. We assume that consortia that were listed as the organizational or marketing partners of 3GPP on its website are closely related. We expect consortia that are allied with $3 \mathrm{GPP}$ to provide more 
fruitful venues for influencing peers' innovation activities related to technologies that $3 \mathrm{GPP}$ standardizes, because the technologies concerned are more likely to be related, too.

The third distinction is between consortia that are technical or marketing-oriented in nature. From each consortium's historical website we obtained information about whether its activities involved drafting of technical specifications. We assume these consortia are involved in feeding technical feature ideas and specification proposals to 3GPP, and thus potentially have a direct impact on the standards that are certified in 3GPP. In contrast, marketing-oriented consortia primarily promote the technologies concerned by providing information for the media and by lobbying governments and other decisionmakers. They also may carry out interoperability testing and certification, but do not develop technical specifications.

We expect that technical consortia are more conducive than marketing consortia to technical spillovers that influence subsequent patenting of inventions. We also argue that this distinction sheds some light on the question of the degree of strategic citation. One would expect that if strategic citation to increase the likelihood of patent validity is driving our dependent variable, both types of consortia should be useful contexts for strategic interactions and alignment. In contrast, if knowledge spillovers rather than strategic citation are primarily driving citations, then technical consortia should be more conducive to them.

We also examine the moderating effect of the technological resources of the patent holder using an interaction variable, consortium connections*patent apps, that is, consortium connections multiplied by the number of patents applied by the cited firm during the year. This variable allows us to assess the potential moderating impact of the (technological) size of the patent holder on the consortium participation effect. We expect that larger technology firms are more effective at translating consortium connections into opportunities to influence others' innovation activities. The sheer volume of technological resources such as patents and experts is expected to enhance the power to influence peers.

Regarding the types of consortia, the results in table 5 confirm expectations. Memberships in informal consortia statistically significantly explain citations whereas the coefficient of memberships in formal standardization organizations is insignificant. The coefficient and odds ratio of formal consortia are actually larger but they are much less precisely estimated. 
Similarly confirming expectations, the strategic and technological scope of the consortium influences the intensity of the effect of consortium memberships. Consortia that are related to 3 GPP are driving the overall effect. The effect is essentially zero for unrelated consortia.

Table 5: Effects of different types of consortia and the moderating effect of technological resources

\begin{tabular}{|c|c|c|c|c|c|c|c|c|}
\hline & \multicolumn{2}{|c|}{ (1) } & \multicolumn{2}{|c|}{ (2) } & \multicolumn{2}{|c|}{ (3) } & \multicolumn{2}{|c|}{ (4) } \\
\hline & $\begin{array}{l}\text { Coef. } \\
\text { (SE) }\end{array}$ & Odds ratios & $\begin{array}{l}\text { Coef. } \\
\text { (SE) }\end{array}$ & $\begin{array}{l}\text { Odds } \\
\text { ratios }\end{array}$ & $\begin{array}{l}\text { Coef. } \\
\text { (SE) }\end{array}$ & $\begin{array}{l}\text { Odds } \\
\text { ratios }\end{array}$ & $\begin{array}{l}\text { Coef. } \\
\text { (SE) }\end{array}$ & $\begin{array}{l}\text { Odds } \\
\text { ratios }\end{array}$ \\
\hline $\begin{array}{l}\text { Informal consortium } \\
\text { memberships }\end{array}$ & $\begin{array}{l}0.0027 * * \\
(0.001)\end{array}$ & $\begin{array}{c}1.0027 * * \\
(0.001)\end{array}$ & & & & & & \\
\hline $\begin{array}{l}\text { Formal consortium } \\
\text { memberships }\end{array}$ & $\begin{array}{l}0.0039 \\
(0.004)\end{array}$ & $\begin{array}{l}1.0039 \\
(0.004)\end{array}$ & & & & & & \\
\hline $\begin{array}{l}\text { Related consortium } \\
\text { memberships }\end{array}$ & & & $\begin{array}{c}0.0156 * * * \\
(0.003)\end{array}$ & $\begin{array}{l}1.0158 * * * \\
(0.003)\end{array}$ & & & & \\
\hline $\begin{array}{l}\text { Unrelated consortium } \\
\text { memberships }\end{array}$ & & & $\begin{array}{l}-0.0003 \\
(0.0002)\end{array}$ & $\begin{array}{c}0.9997 \\
(0.0002)\end{array}$ & & & & \\
\hline Marketing consortium & & & & & 0.0422 & 1.0432 & & \\
\hline memberships & & & & & $(0.041)$ & $(0.042)$ & & \\
\hline Technical consortium & & & & & $0.1915 * * *$ & $1.2110^{* * *}$ & & \\
\hline memberships & & & & & $(0.017)$ & $(0.020)$ & & \\
\hline $\begin{array}{l}\text { Consortium } \\
\text { connections }\end{array}$ & & & & & & & $\begin{array}{l}-0.0001 \\
(0.001)\end{array}$ & $\begin{array}{l}0.9999 \\
(0.001)\end{array}$ \\
\hline $\begin{array}{l}\text { Cons. connections* } \\
\text { patent apps }\end{array}$ & & & & & & & $\begin{array}{l}2.83 \mathrm{e}-06^{* *} \\
(1.14 \mathrm{e}-06)\end{array}$ & $\begin{array}{c}1.0000 * * \\
(1.14 \mathrm{e}-06)\end{array}$ \\
\hline Patent apps & & & & & & & $\begin{array}{l}-0.0005^{*} \\
(0.0002)\end{array}$ & $\begin{array}{l}0.9995^{*} \\
(0.0002)\end{array}$ \\
\hline 3GPP connections & $\begin{array}{l}0.0171 * * * \\
(0.004)\end{array}$ & $\begin{array}{l}1.0173 * * * \\
(0.004)\end{array}$ & $\begin{array}{l}0.0111 * * * \\
(0.003)\end{array}$ & $\begin{array}{l}1.0112 * * * \\
(0.003)\end{array}$ & $\begin{array}{l}0.0142 * * * \\
(0.003)\end{array}$ & $\begin{array}{c}1.0143 * * * \\
(0.003)\end{array}$ & $\begin{array}{l}0.0133 * * * \\
(0.004)\end{array}$ & $\begin{array}{l}1.0134 * * * \\
(0.004)\end{array}$ \\
\hline Patent age dummies & & $Y$ & Y & $Y$ & r & & $\mathrm{Y}$ & \\
\hline Observations & & 84 & 61 & 84 & 61 & & 58 & \\
\hline Groups & & 43 & 10 & 43 & & & 10 & \\
\hline $\mathrm{Chi}^{2}$ & & 4.39 & 689 & .77 & $85^{\prime}$ & & 631 & \\
\hline Prob $>$ chi $^{2}$ & & 0 & ( & & ( & & 0 & \\
\hline Log Likelihood & -15 & 2.77 & -155 & 4.412 & -181 & .963 & -153 & .47 \\
\hline Cited firms & & 3 & 4 & 3 & 4 & & 43 & \\
\hline
\end{tabular}

Notes: Dependent variable is an indicator for whether a patent was cited by an essential patent applied in year $t$. Estimation method is conditional logit with fixed effects at the patent level. Unit of analysis is cited patent. Standard errors, clustered on patents, are in parentheses under the coefficients. $* \mathrm{p}<.10 ; * * \mathrm{p}<.05 ; * * * \mathrm{p}<.01$

The third specification in table 5 splits the consortium memberships to those in technical and marketing consortia. As expected, the effect of technical consortia is much larger and statistically more significant than that of marketing consortia. This supports our assumption that spillovers rather than purely strategic citing behaviours are driving subsequent citations. 
In the last specification in table 5 we find that firms' technological resources (measured by annual patent applications) statistically significantly moderate the consortium participation effect on the likelihood to be cited in subsequent patents by peers. However, the odds ratios seem economically insignificant, partly because the mean number of patent applications is in the hundreds and many of the sampled firms have thousands of annual applications. A single additional patent application has only a negligible effect on the odds of citation, but hundreds of additional patent applications may already begin to amplify the effect of consortium connections. Our hypothesis that larger technology firms are more effective at translating consortium connections into opportunities to influence others' innovation activities is thus weakly supported. The moderating effect probably is meaningful only for very large technology firms.

In robustness analyses at the cited patent level, we tested whether the consortium coordination effect also matters for 3GPP members' patents that are not declared as essential for the UMTS standard. We found no significant effect on non-essential patents, even though we focused on patents in the same wireless technology classes. Thus, our results suggest pre-standardization consortia are an effective way to coordinate $R \& D$ around the relevant compatibility standards but not more generally to influence innovation in the same technological classes. We also examined whether the consortium variables enhance the productivity of invention per se. The literature on R\&D consortia (e.g., Branstetter and Sakakibara, 1998) suggest that shared R\&D in consortia enables firms to internalize knowledge externalities and hence enhance the productivity of R\&D. We found mixed evidence for this idea. Whereas consortium connections are positively associated with subsequent production of essential patents, the result is not corroborated by the differences-in-differences analysis. Hence, our results do not provide strong support for the idea that standardization consortia also enhance the productivity of invention.

Because fixed-effects estimation considerably reduces the number of observations, we also estimated with a random-effects specification taking into account the overall sample and using mean variables to control for permanent characteristics (Wooldridge, 2002, pp. 487488, 679). This Chamberlain-style procedure includes the means of the time-varying explanatory variables as additional regressors in the random-effects procedure, assuming that the permanent characteristics are normally distributed conditional on the explanatory variables. According to Wooldridge (2002), this method is less robust but more efficient than 
the conditional fixed-effects approach. The results are presented in appendix 6 and confirm the findings of the fixed-effects estimation. We also checked the robustness of our results using a linear probability model. These results are presented in appendix 7 and confirm the findings presented in the body of the paper, with one exception: according to the linear probability model, formal consortia are more important for subsequent innovation than are informal consortia. Finally, we checked whether our results are driven by patents that are cited only once over the study period by other $3 \mathrm{G}$ participants. Excluding these patents in a robustness test did not change our results.

To summarize our analyses at the cited patent level, our main hypothesis that participation in technical consortia facilitates coordination of firms' innovation policies is supported. This result is robust to the choice of method and variable used to capture the participation effect. The magnitude of the effect depends on the nature of the consortia. In the conditional logit estimations, the coordination effect is economically and statistically more significant for informal rather than formal consortia, for consortia that are technologically and strategically related rather than unrelated to $3 \mathrm{GPP}$, and for technical rather than marketing-oriented consortia. Finally, we exploited a merger in the set of consortia to check the statistical identification of the main coordination effect. Exogenous changes in consortium connections caused by the merger positively and statistically significantly influenced subsequent citations by peers.

We next conduct an analysis at the firm-pair level of the impact of co-memberships in informal industry consortia on the likelihood of cross-citation. This approach follows the analysis of cooperation among universities by Agrawal and Goldfarb (2008). The dataset is now set up as a panel of possible firm pairs from the list of 47 firms that ever cite other $3 \mathrm{GPP}$ members' patents or whose patents ever get cited by other members. The full panel has six years and 47*47-47 observations each year (we account for the direction of citation and exclude self citations). We thus have almost 13000 firm-pair-years in total, but in estimations we narrow this sample down to more relevant sets of observations. We also restrict the analysis to the years between 2000 and 2003 to focus on the OMA merger "treatment" impact.

In all specifications, we exclude pairs where the potentially cited firm has never actually been cited during the period of study, because these may include firms that did not have relevant 
intellectual property prior to the study period. We then have 7912 firm-pair observations over the four-year period. Table 6 provides means and cross-tabulations for these data. Citation from firm $\mathrm{j}$ to firm $\mathrm{i}$ is a rare occurrence; only $4.6 \%$ of the firm-pair-year observations are associated with a citation. Consortium activities, in contrast, are quite common. $50.5 \%$ of firm pairs include firms that are co-members of either OMA (after 2001) or a consortium that merged with OMA in 2002 (for 2000-2001). 60.9\% of firm-pair-years have firms that are both members in the same informal consortia, other than OMA or its constituent consortia. The cross-tabulations show a strong correlation between citation and OMA-related comembership, and between OMA and other consortia co-memberships. The correlation between co-membership in other consortia and cross-citation is also positive but less pronounced.

Table 6: Sample statistics for the firm-level co-membership analysis $(2000-2003 ; \mathrm{N}=7912)$

\begin{tabular}{lccccccc}
\hline & & \multicolumn{2}{c}{ OMA co- } & \multicolumn{2}{c}{$\begin{array}{c}\text { Other consortia } \\
\text { co-membership }\end{array}$} & \multicolumn{2}{c}{ Citation } \\
\hline Variable & Mean & 0 & 1 & 0 & 1 & 0 & 1 \\
\hline Citation & 0.046 & 0.033 & 0.058 & 0.037 & 0.051 & NA & NA \\
OMA co-membership & 0.505 & NA & NA & 0.214 & 0.691 & 0.498 & 0.642 \\
Consortia co-membership & 0.609 & 0.380 & 0.834 & NA & NA & 0.605 & 0.680 \\
\hline
\end{tabular}

In table 7 we present differences-in-differences results from the analysis of the impact of consortium co-memberships on the likelihood of citation from patent of firm $\mathrm{j}$ to a patent of firm i. The empirical setting is not ideal because of the few positive observations of the dependent variable (4.6\%) and for this reason the estimation model is kept as simple as possible. We find that the key explanatory variable capturing OMA co-membership after 2001 is positive and statistically significant in most specifications. Thus, two firms that became OMA co-members because of the merger were significantly more likely to cite each other's patents. According to odds ratios for specification 1 (not reported in the table), compared to a situation where firms are not members of OMA consortia, a co-membership in OMA or its predecessor consortia increases the odds that a firm pair experiences a cross-citation by $33 \%$, whereas a co-membership in OMA after 2001 increases these odds by 90\%. These numbers appear to be very high, but considering that the raw probability of citation is very low, then even with the increased odds the risk of citation remains fairly low. These results are reasonably robust to the exclusion of pairs where the potential citing firm has never actually 
cited another 3GPP member firm's patents in its essential patents (accounting for the concern that some firms may not be "at risk" of sending a citation to 3GPP peers) and to the addition of fixed effects for cited firms. These results are reported in specifications 2 and 3.

In all specifications we control for co-memberships in other informal consortia, because they will reflect the general tendency of firms in this field to join industry consortia. In earlier estimations, and also in correlation analyses within the current sample, the relationship between other informal consortium connections and cross-citations is rather strong, but in the estimation models here, the coefficient of co-memberships in other consortia is usually insignificant. This is in part influenced by the multicollinearity between OMA and other consortia co-memberships: firms that join OMA-related consortia are also likely to join other informal consortia. The collinearity between OMA and other co-memberships is less severe in earlier years of the study period, because of the lower concentration of citing firms. Hence, if we exclude the year 2003 from the analyses, this variable becomes statistically significant. Nevertheless, even when this variable is excluded, the coefficients of OMA variables retain their levels of significance, and hence the main results are not affected by the multicollinearity.

The last specification in table 7 includes dummies (fixed effects) for the citing firms. Whereas there are 43 firms whose patents were cited during our period of study, there are only 17 firms from which citations originate, so this end of the cross-citation network is highly concentrated. Bekkers, Bongard and Nuvolari (2011) make similar observations about these data. In table 7, we are able to identify 13 citing firm dummies for the period 2000-2003. In this specification, the OMA co-membership and the other consortia co-membership variables have positive and statistically significant effects, but the coefficient of OMA co-membership after the merger becomes insignificant. This seems to be driven by the concentration of citing firms, particularly after 2001. In our essential patent database, we have 367 essential patents applied in 2002 with citations to earlier patents by 3GPP members. Of these 367 citations, full $87 \%$ are made by one of two firms, InterDigital and Qualcomm. In 2003 the share of citations by these two firms is even higher, $96 \% .{ }^{14}$ Thus, their firm dummies capture all the statistically relevant information about the likelihood of citation among firm pairs after 2001. For the same reasons, we cannot identify any effect of consortia co-memberships after including firm-

\footnotetext{
${ }^{14}$ Before 2002, the shares of InterDigital and Qualcomm were somewhat smaller; for example, in 2000, there were 12 citing firms and the shares of InterDigital and Qualcomm were 30\% and 31\%, respectively.
} 
pair fixed effects. Nevertheless, the other co-membership variables still suggest that there is a strong relationship between consortia and citations.

Although the statistical analysis of the effects of firm-pair co-memberships is hampered by data concentration, these data are interesting from the perspective of individual firms' competitive strategies. Qualcomm and InterDigital are not the most active citing firms by chance; they are the only firms in the sample that have followed a business model primarily focused on commercialization of intellectual property (although Qualcomm also produces chipsets that are components for mobile phones). Whereas the likes of Nokia, Matsushita, and Motorola were very active in IP creation, enforcement, and trading, they were primarily manufacturers of network or terminal equipment. At the time of this study, Qualcomm was primarily an IP provider, and InterDigital was purely so.

We interpret these data as indirect evidence of the implications of different business models through strategic behavior in terms of essential patent declarations. One interpretation for these data and estimation results is that InterDigital and Qualcomm actively utilize discussions in industry consortia to assess how the UMTS compatibility standard will evolve in the near term, and then attempt to place their own stakes in the IP space by patenting inventions and declaring them (potentially) essential for the standard. 
Table 7: Probability of citation between firms i and $\mathbf{j}$ : differences-in-differences approach

\begin{tabular}{|c|c|c|c|c|c|c|c|c|}
\hline \multirow[b]{2}{*}{ Citation } & \multirow{2}{*}{$\begin{array}{c}(1) \\
\text { Coef. } \\
\text { (SE) }\end{array}$} & \multicolumn{3}{|c|}{ (2) } & \multicolumn{2}{|l|}{ (3) } & \multicolumn{2}{|l|}{ (4) } \\
\hline & & $\begin{array}{c}\mathrm{OR} \\
\text { (SE) }\end{array}$ & $\begin{array}{l}\text { Coef. } \\
(\mathrm{SE})\end{array}$ & $\begin{array}{c}\text { OR } \\
\text { (SE) }\end{array}$ & $\begin{array}{l}\text { Coef. } \\
(\mathrm{SE})\end{array}$ & $\begin{array}{c}\text { OR } \\
\text { (SE) }\end{array}$ & $\begin{array}{l}\text { Coef. } \\
(\mathrm{SE})\end{array}$ & $\begin{array}{c}\mathrm{OR} \\
\text { (SE) }\end{array}$ \\
\hline \multirow[t]{2}{*}{ Constant } & -2.805 & & $-1.277^{* * *}$ & & $-3.853^{* * *}$ & & $-3.036^{* * *}$ & \\
\hline & $(0.164)$ & & $(0.166)$ & & $(0.713)$ & & $(0.471)$ & \\
\hline \multirow[t]{2}{*}{ OMA co-membership } & $0.290^{* *}$ & $1.336^{* *}$ & 0.259 & 1.296 & 0.196 & 1.216 & $0.437^{* *}$ & $1.549^{* *}$ \\
\hline & $(0.139)$ & $(0.186)$ & $(0.169)$ & $(0.219)$ & $(0.167)$ & $(0.203)$ & $(0.220)$ & $(0.341)$ \\
\hline \multirow{2}{*}{$\begin{array}{l}\text { OMA co-membership } \\
\text { after } 2001\end{array}$} & $0.642^{* *}$ & $1.900^{* *}$ & $0.532^{*}$ & $1.703^{*}$ & $0.644^{* *}$ & $1.904^{* *}$ & -0.137 & 0.872 \\
\hline & $(0.265)$ & $(0.504)$ & $(0.280)$ & $(0.477)$ & $(0.270)$ & $(0.514)$ & $(0.322)$ & $(0.281)$ \\
\hline \multirow[t]{2}{*}{ Consortia co-membership } & 0.208 & 1.231 & 0.222 & 1.249 & -0.250 & 0.779 & $1.208^{* * *}$ & $3.348^{* * *}$ \\
\hline & $(0.153)$ & $(0.188)$ & $(0.184)$ & $(0.230)$ & $(0.170)$ & $(0.132)$ & $(0.248)$ & $(0.831)$ \\
\hline \multirow[t]{2}{*}{ Coding Technologies } & & & & & & & 0.511 & 1.667 \\
\hline & & & & & & & $(0.616)$ & $(1.028)$ \\
\hline \multirow[t]{2}{*}{ Ericsson } & & & & & & & $1.027^{* *}$ & $2.793^{* *}$ \\
\hline & & & & & & & $(0.423)$ & $(1.181)$ \\
\hline \multirow[t]{2}{*}{ InterDigital } & & & & & & & $4.265^{* * *}$ & $71.181^{* * *}$ \\
\hline & & & & & & & $(0.524)$ & (37.274) \\
\hline \multirow[t]{2}{*}{ IP Wireless } & & & & & & & -0.210 & 0.811 \\
\hline & & & & & & & $(0.742)$ & $(0.601)$ \\
\hline \multirow[t]{2}{*}{ Matsushita } & & & & & & & $1.219^{* * * *}$ & $3.384^{* * *}$ \\
\hline & & & & & & & $(0.460)$ & $(1.558)$ \\
\hline \multirow[t]{2}{*}{ Mitsubishi } & & & & & & & $-1.522^{* *}$ & $0.218^{* *}$ \\
\hline & & & & & & & $(0.665)$ & $(0.145)$ \\
\hline \multirow[t]{2}{*}{ Motorola } & & & & & & & $-1.091^{*}$ & $0.336^{*}$ \\
\hline & & & & & & & $(0.560)$ & $(0.188)$ \\
\hline \multirow[t]{2}{*}{ NEC } & & & & & & & -0.338 & 0.713 \\
\hline & & & & & & & $(0.513)$ & $(0.366)$ \\
\hline \multirow[t]{2}{*}{ Nokia } & & & & & & & $1.275^{* * *}$ & $3.580^{* * *}$ \\
\hline & & & & & & & $(0.413)$ & $(1.479)$ \\
\hline \multirow[t]{2}{*}{ Nortel Networks } & & & & & & & $0.872^{*}$ & $2.393^{*}$ \\
\hline & & & & & & & $(0.451)$ & (1.078) \\
\hline \multirow[t]{2}{*}{ Qualcomm } & & & & & & & $3.099^{* * * *}$ & $22.183^{* * *}$ \\
\hline & & & & & & & $(0.461)$ & $(10.220)$ \\
\hline \multirow[t]{2}{*}{ Tantivy Communications } & & & & & & & 0.186 & 1.204 \\
\hline & & & & & & & $(0.479)$ & $(0.577)$ \\
\hline Texas Instruments & & & & & & & (omitted) & \\
\hline Observations & 7912 & & 2196 & & 7912 & & 2196 & \\
\hline
\end{tabular}

Notes: Dependent variable: binary for citation from $\mathrm{j}$ to $\mathrm{i}$. All specifications exclude pairs where firm $\mathrm{i}$ was never cited during 2000-2003. Specification (2) also excludes pairs where firm j never cited patents of other 3GPP members in 2000-2003. Specification (3) adds fixed effects (dummies) for cited firms. Specification (4) adds dummies for citing firms that are listed on the lower part of the table. Estimation method is logit with differences-in-differences variables to utilize the exogenous variation from the merger of consortia that led to Open Mobile Alliance (OMA) in 2002. 2000-2001 is the pre-merger period and 2002-2003 is the post-merger period. Year dummies are included in all specifications but not reported. 
However, while doing so, they may strategically make citations to consortium peers' earlier patents to pre-emptively limit their own short-term returns but also to reduce the likelihood of validity challenges. Lampe (2012) suggests that firms are more likely to cite relevant prior art when the invented technology is expected to be very profitable and less likely to do so when their own portfolio is very large and they can effectively defend their patents. The business models of both Qualcomm and InterDigital are in fundamental ways based on inserting patents into wireless standards, which can result in some extremely profitable patents. Their patent portfolios are also substantially smaller than those of many of their wireless technology peers. Hence, one might expect them to be extraordinarily active in citing wireless peers' prior art, which they may learn about in consortium discussions. Although their citation incentives are attenuated by their non-practicing entity status in wireless technologies for which reason they might pursue more aggressive litigation strategies than operating company peers, they are very highly dependent on the validity of their patents.

We conclude these analyses by noting that co-memberships in consortia, particularly those related to Open Mobile Alliance, are significantly associated with the likelihood of crosscitation among 3GPP member firms in their essential patents. If a firm attended a relevant technical consortium, other members of the same consortium were significantly more likely to cite its earlier patents in their own current patents that eventually led to essential IP declarations. Thus, this firm-pair-level analysis highlights the mechanism that generates the results in the earlier patent-level panel analyses. However, there are some empirical challenges with these analyses. 
First, the raw probability of citation is very low because relatively few firm pairs generate cross-citations. Second, the citing behavior is highly concentrated, which hinders the statistical analysis. Most firms in the dataset (firms whose patents ever cite or get cited) have rather few cited patents or cite few patents of other firms, whereas the two leading IP firms, Qualcomm and InterDigital, dominate the activity and are thus associated with enormous fixed effects. Their strategies highlight the implications of business models. With respect to wireless communication technologies, these two firms operate almost exclusively in the IP market rather than the product market, for which reason their strategic drivers are very different from most other firms who also manufacture products. Nevertheless, industry consortia, including the OMA consortium after the merger of seven constituent consortia, appear to be central venues in which these and other firms learn about technologies related to the UMTS standard on which they subsequently build further inventions.

\section{Conclusion}

This paper analyzes the impact of firms' participation in ICT consortia on knowledge sharing and coordination of innovation strategies related to compatibility standards. We use data on participation in 32 ICT consortia and prior art citations in essential patents filed by participants in the 3GPP standardization process. To empirically identify the effect of consortium connections, we exploit a merger in the network of consortia as a quasiexperiment that exogenously changed consortium connections of members.

Our empirical analysis highlights the impact of the patent holder's position in the consortium network on the likelihood of having its patents cited by other participants in subsequent research. The more central the firm is in the consortium network, the greater the likelihood of its patents being cited by other firms in subsequent patents that are declared essential for the UMTS standard. This result is stronger for consortia that are formally allied with (related to) 3GPP, whereas the result is weaker but still positive and statistically significant for consortia unrelated to $3 \mathrm{GPP}$. Our findings also suggest that technical consortia are more effective vehicles for coordinating standards-related innovation compared to marketing consortia. Finally, whereas participation in informal consortia has a positive and statistically significant impact on the likelihood to be cited by subsequent research, the same does not hold for more 
formal consortia such as other standard-setting organizations, although this result is not completely robust to different estimation methods.

The main result that consortium participation facilitates coordination of firms' innovation activities is confirmed by a difference-in-difference analysis using a merger in the network of consortia as a source of exogenous variation. Additional evidence for this result is also provided by a firm-pair-level approach where we highlight the knowledge transmission mechanism through the effect of firm pairs' co-memberships in specific consortia. The firmpair level analyses also highlight the implications of firms' business models. The two firms InterDigital and Qualcomm that dominate the citing behavior in the latter half of our period of study operate under an IP-based business model, whereas other firms also participate in the product markets.

Based on the variety of empirical evidence, we suggest that industry consortia potentially improve incentives for $R \& D$ because they enable the internalization of knowledge-creation externalities. They may also speed up standardization by facilitating both committee and market processes and their interactions. However, in the standard-setting context our findings also raise questions. Our results demonstrate that standardization takes place not only in the marketplace and in formal standard-setting organizations, but also in informal upstream consortia.

Lack of transparency and openness of informal consortia may present challenges for less prominent innovators. Because of the private and opaque nature of informal consortia, it can be difficult for an innovating entrant to understand who makes decisions about standardization, where, when, and through what process. During and preceding the period of study, many ICT consortia were formed by a small group of industry leaders, and the consortia tended to have a pre-set agenda and a tiered membership structure where the founding firms had a more powerful position than latecomers. Moreover, we found some evidence of technological resources enhancing the effect of consortium connections on subsequent innovation for technology giants. Even if smaller innovators can find their way to the right meetings, their impact may be weaker.

Moreover, when standard setting is effectively distributed to dozens of consortia, each with substantial membership fees and frequent meeting schedules, participation can become prohibitively costly for cash-constrained firms. Small firms are likely to have few technical 
experts who are able to travel to consortium meetings, and with several potentially relevant consortia, this may simply not be possible.

Finally, major firms have justified consortia as a method of speeding up standards development. Whereas this is a laudable goal for any industry, the actual cause of accelerated outcomes from consortia may be exactly that smaller firms and those who disagree with a subset of industry leaders are not participating. Further research would need to be conducted to properly understand the welfare implications of the effect of upstream consortia in potentially narrowing down the pool of innovations that are subsequently incorporated in the ex-ante compatibility standard.

We suggest that these novel results on the organization of compatibility standardization call for a rethinking of standard-setting policies. Innovation and competition policymakers might include informal upstream consortia in their frameworks for standardization policy, because this is where a significant part of coordination is done. Simple requirements for open membership, publicly available meeting and decision documents, and public disclosure of decision-making rules and rights of different members might go a long way toward dispelling the undemocratic reputation of informal consortia. By the same token, our results show that innovating firms who want to commercialize new products or technologies in network industries must deploy a standard-setting strategy that involves participation not only in formal standard-setting organizations but also in informal consortia to optimize opportunities to influence and align strategies with peers.

The main limitation of our study is the well-known issue related to inference drawn from patent cross-citations (Alcacer and Gittelman, 2006; Thompson and Fox Kean, 2004). In particular, it is not known whether the consortium effect actually demonstrates knowledge flows and coordination of innovation, or whether participation in consortia simply makes firms aware of each other's patents and therefore compels them to include citations to peers' earlier patents for strategic reasons. Corroborating the results with other than patent data, such as meeting documents or interview-based case studies might be desirable. 


\section{REFERENCES}

Agrawal, A. and A. Goldfarb (2008). Restructuring Research: Communication Costs and the Democratization of University Innovation. American Economic Review 98(4): 1578-90.

Alcacer, J. and M. Gittelman (2006). Patent Citations as a Measure of Knowledge Flows: The Influence of Examiner Citations. The Review of Economics and Statistics. 88(4): 774-779

Aldrich, H., M. Bolton, T. Baker and T. Sasaki (1998). Information Exchange and Governance Structures in U.S. and Japanese R\&D Consortia: Institutional and Organizational Influences. IEEE Transactions on Engineering Management. 45(3): 263-275

Aldrich, H. and T. Sasaki (1995). R\&D consortia in the United States and Japan. Research Policy. 24: 301-316

Allison, J. and M. Lemley (1998). Empirical Evidence on the Validity of Litigated Patents. American Intellectual Property Law Association Quarterly Journal 26: 185-277.

Anton, J.J. and D. Yao (1995). Standard-Setting Consortia, Antitrust, and High-Technology Industries. Antitrust Law Journal 64(1): 247-65.

Ballester, C., A. Calvo-Armengol and Y. Zenou (2006): Who's Who in Networks. Wanted: the Key Player. Econometrica 74(5): 1403-1417.

Bekkers, R. R. Bongard and A. Nuvolari (2011). An Empirical Study on the Determinants of Essential Patent Claims in Compatibility Standards. Research Policy 40: 1001-15.

Biddle, Brad (2012). How Many Standards in a Laptop? Paper presented at the NBER conference on Standards, Patents and Innovation, Tucson AZ, January 2012.

Branstetter, L. and M. Sakakibara (1998). Japanese Research Consortia: A microeconometric Analysis of Industrial Policy. The Journal of Industrial Economics. 46: 207-233

Brodley, J.F. (1990). Antitrust Law and Innovation Cooperation. Journal of Economic Perspectives. 4: 97-112

Cargill, C. F. (2001). The Role of Consortia Standards in Federal Government Procurement in the Information Technology Sector: Towards a Redefinition of a Voluntary Consensus Standards Organization. White paper submitted to the House of Representatives SubCommittee on Technology, Environment, and Standards

CEN (2012). ICT Standards Consortia. Retrieved on June 6, 2012 from http://www.cen.eu/cen/sectors/sectors/isss/consortia/pages/default.aspx.

Choi, J.P. (1993). Cooperative R\&D with Product Market Competition. International Journal of Industrial Organization. 11: 553-571 
Chiao, B. J. Lerner and J. Tirole (2007). The Rules of Standard-Setting Organizations: An Empirical Analysis. Rand Journal of Economics 38(4): 905-930.

Chung, S., H. Singh and K. Lee (2000). Complementarity, status similarity and social capital as drivers of alliance formation. Strategic Management Journal. 21: 1-22

D'Aspremont, C., and A. Jacquemin (1988). Cooperative and Noncooperative R\&D in Duopoly with Spillovers. American Economic Review. 78(5): 1133-1137

DeLacey, B., K. Herman, D. Kiron, J. Lerner (2006). Strategic Behavior in Standard-Setting Organizations. Unpublished paper circulated in the Social Science Research Network (www.ssrn.com).

Dokko, G. and L. Rosenkopf (2010). Social Capital for Hire? Mobility of Technical Professionals and Firm Influence in Wireless Standards Committees. Organization Science. 21(3): 677-695

Egyedi, T.M. (2001). Beyond Consortia, Beyond Standardization? New Case Material and Policy Threads. Report for the European Commission, October. Delft University of

Technology.

Farrell J. and T. Simcoe (2011). Choosing the Rules for Consensus Standardization. Unpublished manuscript. Electronic copy available at: http://ssrn.com/abstract=1396330.

Fershtman C. and N. Gandal (2011). Direct and indirect knowledge spillovers: the "social network" of open-source projects. RAND Journal of Economics. 42: 70-91

Hall, B., A. Jaffe and M. Trajtenberg (2001). The NBER Patent Citations Data File: Lessons, Insights and Methodological Tools" NBER working paper 8498.

Hawkins, R. (1999). The rise of consortia in the information and communication technology industries: emerging implications for policy. Telecommunications Policy. 23(2) : 159-173.

Jorde, T.M. and D. Teece (1990). Innovation and Cooperation: Implications for Competition and Antitrust. Journal of Economic Perspectives. 4: 75-96

Kamien, M., E. Muller and I. Zang (1992). Research Joint Ventures and R\&D Cartels. American Economic Review. 82:1293-1306

Katz, M. (1986). An Analysis of Cooperative Research and Development. Rand Journal of Economics. 17(4) : 527-543.

Katz, M.L., and J.A. Ordover (1990). R\&D Cooperation and Competition. Brookings papers in microeconomics.

Kodama, F. (1986). Japanese innovation in mechatronics technology. Science and Public Policy 13(1): 44-51 
Lampe, R. (2012). Strategic Citation. Review of Economics and Statistics 94(1): 320-333.

Leiponen, A. (2008). Competing Through Cooperation: Standard-Setting in Wireless Telecommunications. Management Science 54(11): 1904-1919.

Leiponen, A. and J. Byma (2009). If You Cannot Block, You Better Run: Small Firms, Cooperative Innovation, and Appropriation Strategies. Research Policy 38: 1478-1488.

Lemley, M. A. (2002). Intellectual Property Rights and Standard Setting Organizations. California Law Review 90: 1889-1990.

MWIF (2000). The Mobile Wireless Internet Forum Antitrust Guidelines. Approved and Adopted March 2, 2000. Retrieved from www.mwif.org using the Internet Archive on June 4, 2012.

Pfeffer, J. (1981). Power in Organizations. Ballinger: Cambridge, MA.

Romer, P., and Z. Griliches (1993). Implementing a National Technology Strategy with SelfOrganizing Industry Investment Boards. Brookings Papers on Economic Activity. Microeconomics. 2: 345-399

Rosenkopf, L., A. Metiu and V. George (2001). From the Bottom Up? Technical Committee Activity and Alliance Formation. Administrative Science Quarterly. 46:748-772

Sakakibara, M. (2001). The Diversity of R\&D Consortia and Firm Behavior: Evidence from Japanese Data. Journal of Industrial Economics. 49(2): 181-196.

Simcoe, T. (2012). Standard Setting Committees: Consensus Governance for Shared Technology Platforms. American Economic Review 102(1): 305-336.

Thompson, P. and M. Fox-Kean (2005). Patent Citations and the Geography of Knowledge Spillovers: A Reassessment. American Economic Review. 95(1)

Updegrove, A. (2010). Standard Setting Organizations and Standards List. Last updated in 2010. Retrieved from www.consortiuminfo.com on February 1, 2012.

WSJ (2011). The Android Patent War. Wall Street Journal Online, retrieved on May 6 from http://online.wsj.com/article/SB10001424052970204826704577074523539966352.html. 


\section{Appendix 1: Description cited patents}

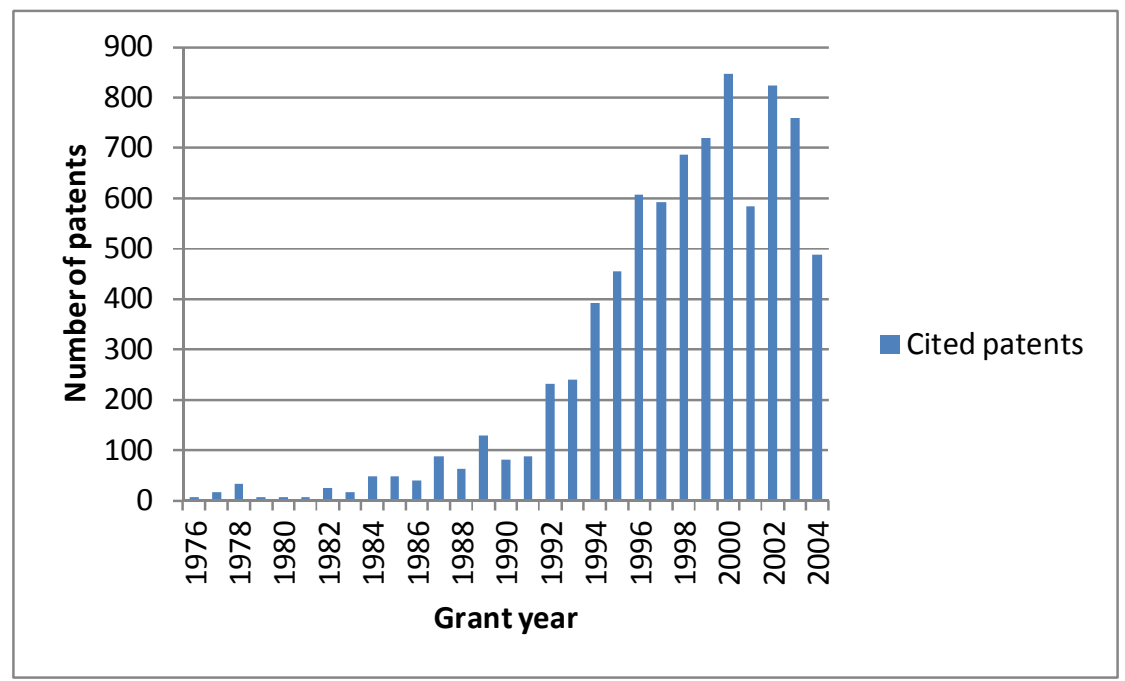

Figure 1: Grant year of the cited patents

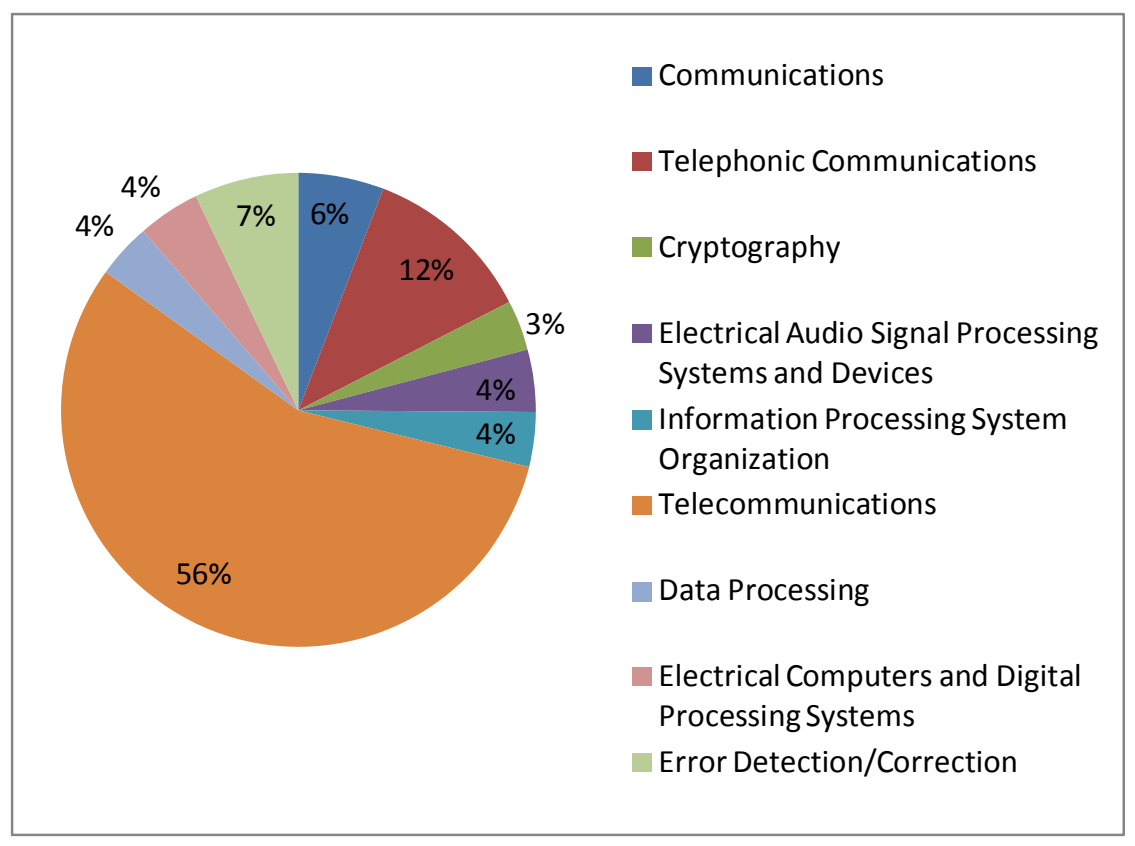

Figure 2: Technological class of the cited patents 


\section{Appendix 2 : Description citing patents}

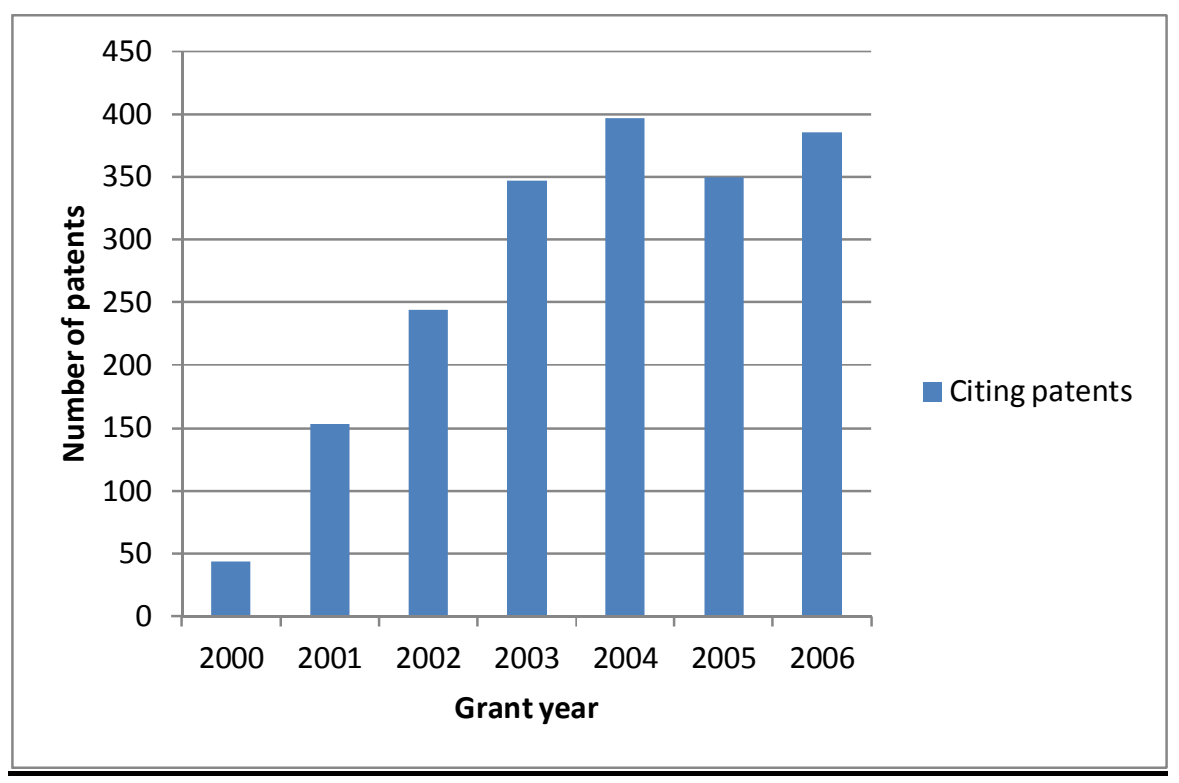

Figure 3: Grant year of the citing patents

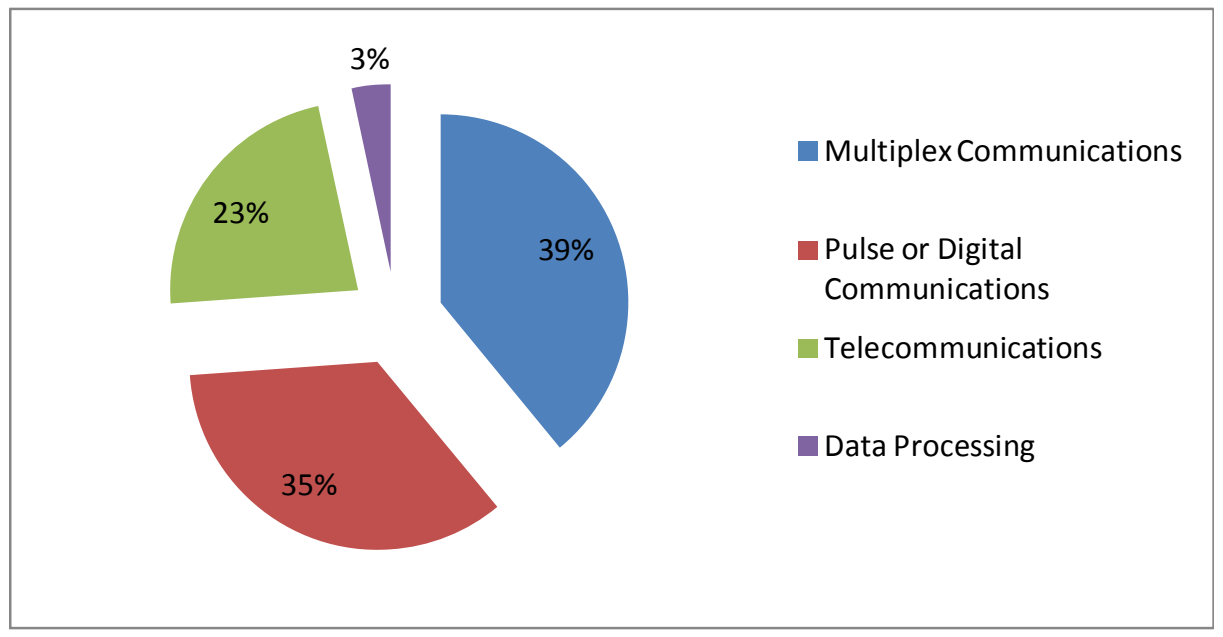

Figure 4: Technological class of the citing patents 


\section{Appendix 3 : List of consortia}

\begin{tabular}{|c|c|c|}
\hline Consortium Name & 3GPP related & Affected by the OMA merger \\
\hline MET & No & No \\
\hline WLANA & No & No \\
\hline SA Forum & No & No \\
\hline ATIS & No & No \\
\hline 3G Americas & No & No \\
\hline CDG & No & No \\
\hline VoiceXML & No & No \\
\hline IPv6 Forum & Yes & No \\
\hline Hiperlan 2 & No & No \\
\hline WiFi Alliance & No & No \\
\hline GSA & Yes & No \\
\hline TTC & Yes & No \\
\hline Bluetooth & No & No \\
\hline GPP 2 & No & No \\
\hline UMTS Forum & Yes & Yes \\
\hline T1 & Yes & No \\
\hline SyncML & No & Yes \\
\hline TTA & No & No \\
\hline UWCC & Yes & No \\
\hline WAP Forum & No & Yes \\
\hline Wireless Village & No & Yes \\
\hline 3GIP & No & No \\
\hline ARIB & Yes & No \\
\hline BWIF & No & No \\
\hline CWTS & No & No \\
\hline ETSI & Yes & No \\
\hline GSM Association & Yes & No \\
\hline MGIF & No & Yes \\
\hline MWIF & No & Yes \\
\hline OMA Alliance & No & No \\
\hline Symbian & No & No \\
\hline WECA & No & No \\
\hline
\end{tabular}




\section{Appendix 4 : Cited patent holders}

\begin{tabular}{|l|l|}
\hline Agere & Matsushita \\
\hline Alcatel & Matra \\
\hline ArrayComm & Microsoft \\
\hline AT\&T Wireless & Mitsubishi \\
\hline Bell South & Motorola \\
\hline BT (British Telecom) & NEC \\
\hline BULL S.A. & Nokia \\
\hline Cisco Systems & Nortel Networks \\
\hline 3Com & OKI Electrics \\
\hline Infineon Technology & Panasonic \\
\hline Ericsson & Qualcomm \\
\hline France Telecom & Racal Instruments \\
\hline Fujitsu Limited & Rogers Wireless \\
\hline Golden Bridge Technology & Samsung \\
\hline Hewlett Packard & Seiko Epson \\
\hline Hughes Network & Sharp \\
\hline ICO Global & Siemens \\
\hline Intel & Sony \\
\hline InterDigital & Texas Instruments \\
\hline LG Electronics & Thomson \\
\hline Lucent & Toshiba \\
\hline
\end{tabular}

\section{Appendix 5 : Control group for the OMA merger}

\begin{tabular}{|c|}
\hline Company Name \\
\hline Hughes Network \\
\hline Agere \\
\hline ArrayComm \\
\hline BT (British Telecom) \\
\hline Bull S.A. \\
\hline Comneon \\
\hline Golden Bridge Technology \\
\hline ICO Global \\
\hline Matra \\
\hline Racal Instruments \\
\hline Rogers Wireless \\
\hline Shanghai Bell \\
\hline
\end{tabular}


Appendix 6: Results using a random effects estimation

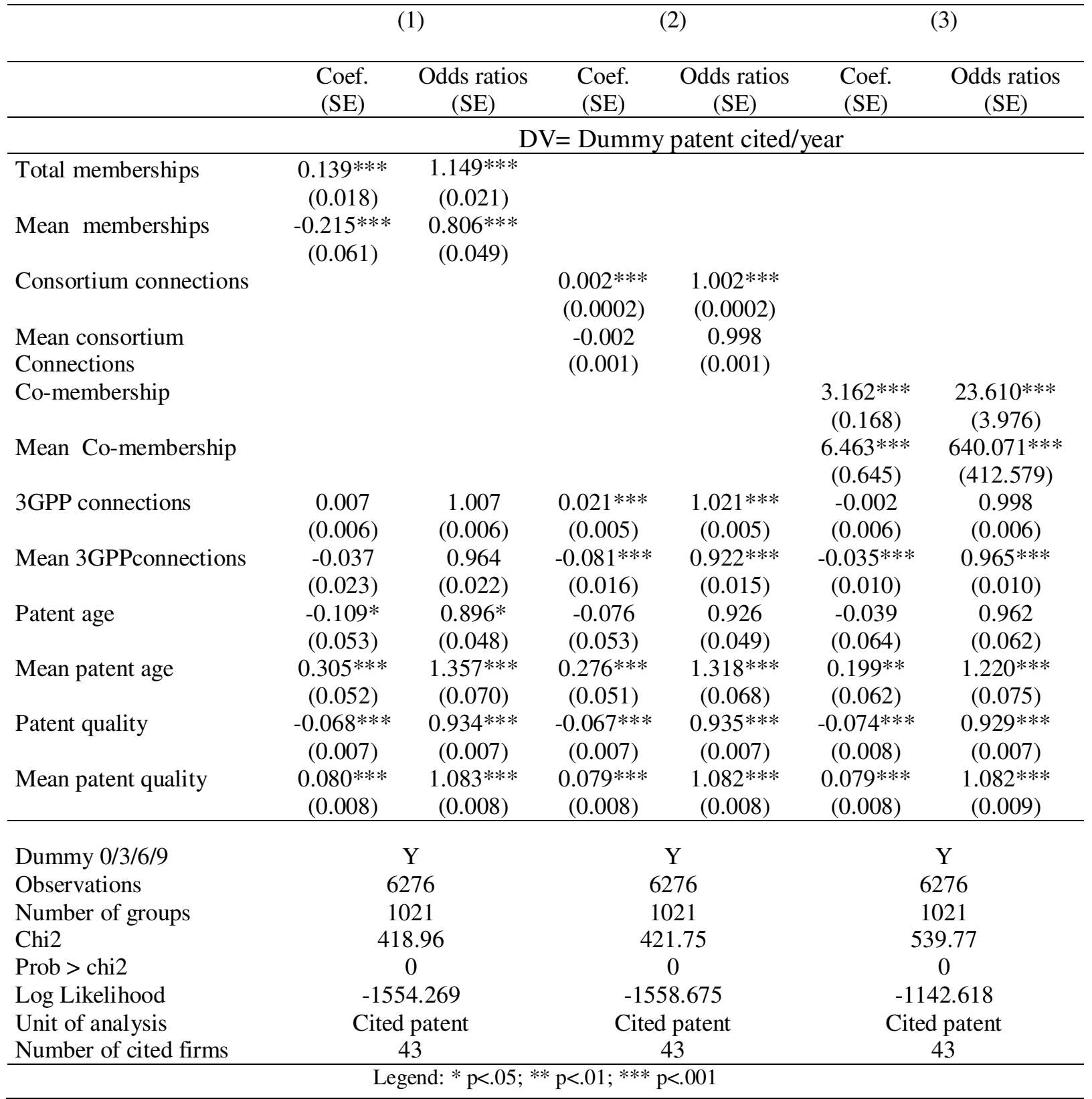

Notes: Dependent variable is an indicator for whether a patent was cited by an essential patent applied in year t. Estimation method is logit with random effects. Dummy 0/3/6/9 are nonlinear effects for patent age. Means are computed at the cited patent level. 


\section{Appendix 7: Regression results with a linear probability model}

Table 7.1 Main results

\begin{tabular}{lcc}
\hline & $(1)$ & $(2)$ \\
\hline Total memberships & $\begin{array}{c}\text { Coef. } \\
\text { (SE) }\end{array}$ & $\begin{array}{c}\text { Coef. } \\
\text { (SE) }\end{array}$ \\
& $0.0050^{* * *}$ & \\
Consortium connections & $(0.0007)$ & $0.0002^{* * *}$ \\
& & $(0.00004)$ \\
3GPP connections & & $0.0007 * *$ \\
& 0.0003 & $(0.0002)$ \\
\hline Dummy Age Cited & $(0.0003)$ & $\mathrm{Y}$ \\
Observations & $\mathrm{Y}$ & 6276 \\
Number of groups & 7297 & 1021 \\
R-sq & 1021 & 0.0975 \\
Unit of analysis & 0.1071 & Cited patent \\
Number of cited firms & Cited patent & 43
\end{tabular}

Notes: Standard errors, clustered on patents, in parentheses under the coefficients.

Legend: ${ }^{*} \mathrm{p}<.05 ; * * \mathrm{p}<.01 ; * * * \mathrm{p}<.001$

Table 7.2 Types of consortia

\begin{tabular}{lcc}
\hline & $(1)$ & $(2)$ \\
\hline & Coef. & Coef. \\
$(\mathrm{SE})$ & $(\mathrm{SE})$ \\
\hline Informal consortium & $0.0022^{*}$ & \\
memberships & $(0.0008)$ & \\
Formal consortium & $0.0172^{* * *}$ & \\
memberships & $(0.0032)$ & $0.0191^{* * *}$ \\
Related consortium & & $(0.0022)$ \\
memberships & & -0.0013 \\
Unrelated consortium & & $(0.0008)$ \\
memberships & & 0.0001 \\
3GPP connections & 0.0006 & $(0.0003)$ \\
& $(0.0003)$ & $\mathrm{Y}$ \\
\hline Dummy Cited Age & $\mathrm{Y}$ & 6276 \\
Observations & 6276 & 1021 \\
Number of groups & 1021 & 0.1049 \\
R-sq & 0.0516 & Cited patent \\
Unit of analysis & Cited patent & 43 \\
Number of cited firms & 43 &
\end{tabular}

Notes: Standard errors, clustered on patents, in parentheses under the coefficients.

Legend: $* \mathrm{p}<.05 ; * * \mathrm{p}<.01 ; * * * \mathrm{p}<.001$ 


\section{Table 7.3 Differences-in-differences estimation of the effects of OMA merger}

\begin{tabular}{lcc}
\hline & $(1)$ & $(2)$ \\
\hline & Coef. & Coef. \\
& $(\mathrm{SE})$ & $(\mathrm{SE})$ \\
\hline OMA connections & $0.0007^{* * *}$ & $0.0006^{* * *}$ \\
Other consortia connections & $(0.0001)$ & $(0.0001)$ \\
& $-0.0001^{*}$ & \\
Formal consortia connections & $(0.00005)$ & -0.00009 \\
& & $(0.00005)$ \\
Informal consortia connections & & $0.0014 * *$ \\
& & $(0.0005)$ \\
OMA connections after & $0.0005^{* * *}$ & $0.0005 * *$ \\
& $(0.0001)$ & $(0.0001)$ \\
Dummy_after & $-0.1831^{* * *}$ & $-0.1811^{* * *}$ \\
3GPP connections & $(0.018)$ & $(0.018)$ \\
& $-0.0014 * * *$ & $-0.0014 * * *$ \\
Dummy Cited Age & $(0.0003)$ & $(0.0003)$ \\
Number of obs & Y & Y \\
Number of groups & 6276 & 6276 \\
R-sq & 1021 & 1021 \\
Unit of analysis & 0.1109 & 0.1169 \\
Number of cited firms & Cited patent & Cited patent \\
& 43 & 43
\end{tabular}

Notes: Standard errors, clustered on patents, in parentheses under the coefficients

Legend: * $\mathrm{p}<.05 ; * * \mathrm{p}<.01 ; * * * \mathrm{p}<.001$ 